\title{
Optimisation of polymer optical fibre based interferometric sensors
}

\author{
Andreas Pospori*, David J. Webb
}

Aston Institute of Photonic Technologies, Aston University, Aston Triangle, Birmingham, B7 4ET, United Kingdom

\begin{abstract}
A numerical model for studying the performance of polymer optical fibre-based interferometric sensors is presented. The strain sensitivity of Fabry-Perot and two-beam interferometric sensors is investigated by varying the physical and optical properties corresponding to frequently used wavelengths. The developed model was used to identify the regimes in which these devices offer enhanced performance over their silica counterparts when used for stress sensing.
\end{abstract}

Keywords: POF, interferometers, strain sensitivity, stress sensing

\section{INTRODUCTION}

Polymer optical fibres (POFs) have received increased interest in recent years due to their different material properties compared to silica based optical fibres (SOFs). Biocompatibility, a higher failure strain and the greater elasticity [1] of POFs are potential advantages over SOFs and these characteristics are useful in the sensor application field. The much lower Young's modulus of POF compared to SOF means that POF sensors have much less effect on any compliant structures that are being monitored and also renders POF based sensors much more sensitive to fibre stress than those fabricated from SOF [2]. The lower Young's modulus also offers sensitivity enhancement when POF is used to sense acoustic waves [3]. However, some considerable drawbacks still exist in POF technology, perhaps the main one being the high fibre loss, which needs to be taken into account when designing interferometric sensors constructed from POF. In the absence of loss the strain sensitivity of a fibre interferometer is proportional to its cavity length, however when interferometers are constructed from POF, increasing the cavity length can result in sensitivity reduction at some point due to the attenuation along the optical path. The loss leads to a reduction in the signal level obtained from two-beam interferometers, while in the case of Fabry-Perot interferometers the finesse can also be significantly reduced. Therefore, evaluating the cavity length that maximises the sensitivity is important in order to optimise the performance of a POF based interferometric fibre sensor.

In this work, a numerical model has been developed in the MATLAB environment where strain sensitivity can be determined for each cavity length of the interferometer. A comparison of strain sensitivities between POF and SOF based interferometric sensors has been made and their optimum cavity length for maximum sensitivity to strain has been found. Moreover, stress sensitivity of POF based sensors is found to be higher than SOF based ones because of their different elastic properties. The results show that POF based interferometric sensors are good candidates for stress sensing.

\section{ANALYSIS AND MODELING}

\subsection{Fabry-Perot interferometer}

A pair of partially reflective, parallel and optical flat mirrors is considered in this model, which is the common arrangement of an etalon (Figure 1). Mirror dimensions are not taking into account in this 1-dimensional numerical modelling. The distance $\mathrm{L}$ between mirrors creates a cavity where constructive interference occurs if the transmitted beams are in phase. For an input electric field $\mathrm{E}_{0}$ normal to the first mirror, part of it reflects back and the remaining is transmitted into the cavity. The process continues as depicted in Figure 1. Therefore, the electric fields can be written as:

$$
E_{1}=t_{1}^{\frac{1}{2}} E_{0}+r_{1}^{\frac{1}{2}} E_{4} \quad E_{2}=E_{1} e^{j k L} e^{-\frac{\alpha}{2} L} \quad E_{3}=r_{2}^{\frac{1}{2}} E_{2} \quad E_{4}=E_{3} e^{j k L} e^{-\frac{\alpha}{2} L} \quad E_{t}=t_{2}^{\frac{1}{2}} E_{2}
$$

where $\alpha$ is the attenuation across the cavity, $r$ is the reflectance of mirrors and $t$ is the transmittance of mirrors considering that $\mathrm{t}=1-\mathrm{r}$. $\mathrm{k}$ is the wavenumber, related to the wavelength $\left(\lambda_{0}\right)$ in vacuum and the refractive index $(\mathrm{n})$ of the material by the equation $\mathrm{k}=\frac{2 \pi \mathrm{n}}{\lambda_{0}}$.

\footnotetext{
Micro-structured and Specialty Optical Fibres IV, edited by Kyriacos Kalli,

Jiri Kanka, Alexis Mendez, Proc. of SPIE Vol. 9507, 95070M · C 2015

SPIE · CCC code: $0277-786 X / 15 / \$ 18 \cdot$ doi: $10.1117 / 12.2180764$
}

Proc. of SPIE Vol. 9507 95070M-1 
Combining the equations above (1), the transmission electric field $\mathrm{E}_{\mathrm{t}}$ can be calculated as:

$$
E_{t}=\frac{t_{1}^{\frac{1}{2}} t_{2}^{\frac{1}{2}} E_{0} e^{j k L} e^{-\frac{\alpha}{2} L}}{1-r_{1}^{\frac{1}{2}} r_{2}^{\frac{1}{2}} e^{2 j k L} e^{-\alpha L}}
$$

For an input $\mathrm{E}_{0}=1$ the transmission intensity $I_{t}=E_{t} E_{t}^{*}$ of Fabry-Perot interferometer equals:

$$
I_{t}=\frac{t_{1} t_{2} e^{-\alpha L}}{1-\left(2 \cos (2 k L) r_{1}^{\frac{1}{2}} r_{2}^{\frac{1}{2}} e^{-\alpha L}\right)+r_{1} r_{2} e^{-2 \alpha L}}
$$

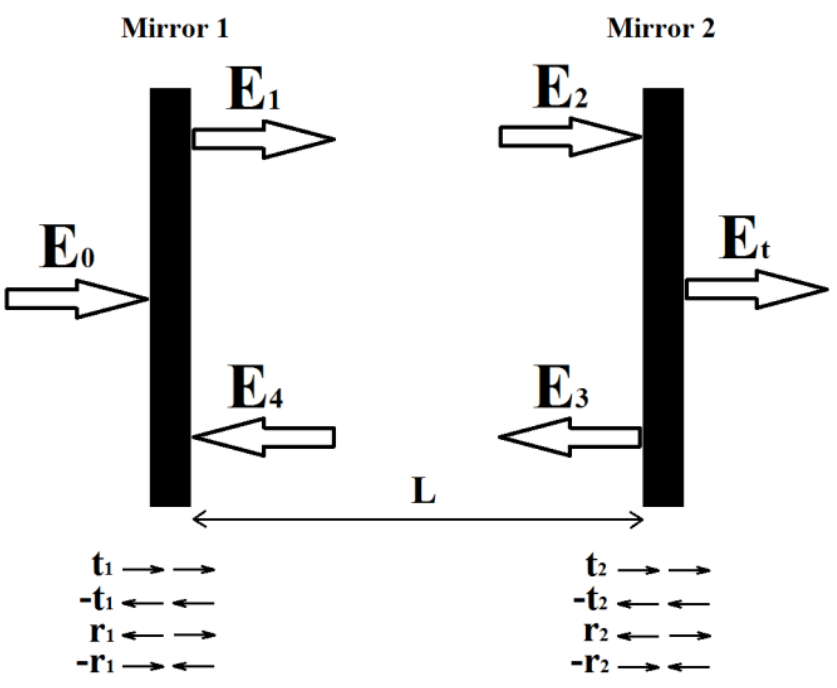

Figure 1: Fabry-Perot interferometer scheme

\subsection{Two-beam interferometer}

In the case of two-beam interferometer, the same electric field $\mathrm{E}_{0}$ travels through two different optical paths as depicted in Figure 2. Merging these two beams (neglecting coupler losses) gives the transmission electric field $\mathrm{E}_{\mathrm{t}}$ :

$$
E_{t}=E_{0}+E_{0} e^{-\alpha L} e^{j(2 k L)}
$$

Considering an input electric field $\mathrm{E}_{0}=1$, the transmission intensity $I_{t}=E_{t} E_{t}^{*}$ of a two-beam interferometer is:

$$
I_{t}=1+e^{-2 \alpha L}+2 e^{-\alpha L} \cos (2 k L)
$$

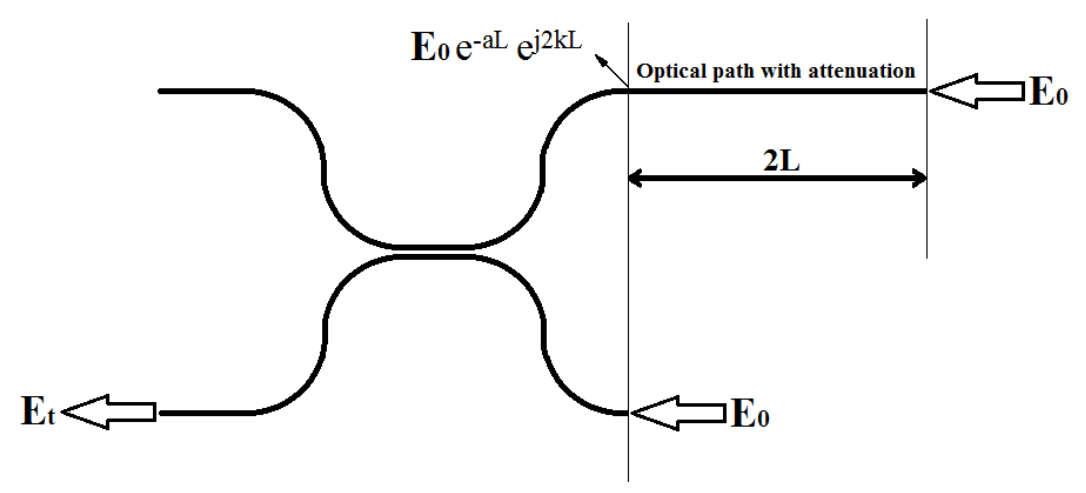

Figure 2: Two-beam interferometer scheme 


\subsection{Modeling methodology}

A numerical model of Fabry-Perot and two-beam interferometer responses has been constructed in the MATLAB environment where the cavity length for maximum strain sensitivity of the sensor can be determined. The model describes the relationship between sensitivity and the key sensor parameters, which are the reflectivity of the mirrors used to form the interferometer, the cavity length and the attenuation. The sensor's strain sensitivity can be determined by differentiating the transmission intensity of interferometer with respects to strain:

$$
\frac{d I_{t}}{d \varepsilon}=\frac{\partial I_{t}}{\partial n} \frac{\partial n}{\partial \varepsilon}+\frac{\partial I_{t}}{\partial L} \frac{\partial L}{\partial \varepsilon}
$$

For a homogeneous and isotropic elastic material the refractive index change due to the elasto-optic effect [4] is:

$$
\frac{\partial n}{\partial \varepsilon}=\frac{n^{3}\left(\mu P_{11}+(\mu-1) P_{12}\right)}{2}
$$

where $\mathrm{P}_{11}$ and $\mathrm{P}_{12}$ are Pockels coefficients, $\mathrm{n}$ is refractive index and $\mu$ is Poisson's ratio of the material under test. The

component $\frac{\partial L}{\partial \varepsilon}$ in equation (6) is actually the cavity length L. The remaining components can be calculated by differentiating the transmission intensity equation with respect to the variables in the expression using MATLAB tools.

\section{RESULTS \& DISCUSSION}

\subsection{Optimum cavity length for maximum strain sensitivity}

The described model above has been used to determine the optical length providing maximum strain sensitivity of FabryPerot or two-beam interferometric fibre based devices. Various parameters have been used during simulations, such as attenuation of fibre, type of material, operating wavelength and reflectivity of mirrors in case of the Fabry-Perot interferometer. The common attenuation $\alpha$ of fibres [5] as well as their refractive indices $n$ for various wavelengths [6-8] are depicted in Table 1. The Pockels coefficients of fused silica are $\mathrm{P}_{11}=0.113$ and $\mathrm{P}_{12}=0.252$ [9] and the Poisson's ratio is $\mu=0.17$ [10]. For poly(methyl methacrylate) (PMMA) fibre these values are $\mathrm{P}_{11}=0.300$ and $\mathrm{P}_{12}=0.297$ [11] and $\mu=0.34$ [12]. Since perfluorinated polymer fibre's (PF-POF) Poisson's ratio and Pockels coefficients are still unknown, values of PMMA have been used, assuming the PF-POF to have similar elasto-optic properties.

Table 1: Common refractive indices and attenuation of each material for frequently used wavelengths

\begin{tabular}{|l|c|c|c|c|c|c|}
\cline { 2 - 7 } \multicolumn{1}{c|}{} & \multicolumn{2}{c|}{ PMMA } & \multicolumn{2}{c|}{ PF-POF (CYTOP) } & \multicolumn{2}{c|}{ Fused Silica } \\
\cline { 2 - 7 } \multicolumn{1}{c|}{} & $\mathrm{n}$ & $\alpha(\mathrm{dB} / \mathrm{km})$ & $\mathrm{n}$ & $\alpha(\mathrm{dB} / \mathrm{km})$ & $\mathrm{n}$ & $\alpha(\mathrm{dB} / \mathrm{km})$ \\
\hline$\lambda=0.650 \mu \mathrm{m}$ & 1.4883 & 200 & 1.3410 & 60 & 1.4565 & 3.5 \\
\hline$\lambda=0.850 \mu \mathrm{m}$ & 1.4840 & 2000 & 1.3390 & 40 & 1.4525 & 1.0 \\
\hline$\lambda=1.050 \mu \mathrm{m}$ & 1.4817 & $\sim 8000$ & 1.3370 & 25 & 1.4498 & 0.5 \\
\hline$\lambda=1.350 \mu \mathrm{m}$ & 1.4750 & $\sim 100000$ & 1.3360 & 20 & 1.4464 & 0.3 \\
\hline$\lambda=1.550 \mu \mathrm{m}$ & 1.4710 & $\sim 100000$ & 1.3355 & 20 & 1.4440 & 0.2 \\
\hline
\end{tabular}

Using equation (3) for a PMMA POF based Fabry-Perot sensor at $\lambda=0.850 \mu \mathrm{m}$ and considering $80 \%$ reflectivity mirrors, the optimum cavity length for maximum strain sensitivity is $23.74 \mathrm{~cm}$ (Figure 3). Unity input power is assumed in all figures. Increasing the reflectivity of the mirrors to $90 \%$, the same maximum sensitivity levels can be achieved with a shorter cavity length of $11.35 \mathrm{~cm}$ (Figure 4). However, a PMMA POF based sensor at $\lambda=1.550 \mu \mathrm{m}$, where the typical attenuation is $1 \mathrm{~dB} / \mathrm{cm}$, has an optimum cavity length of $0.23 \mathrm{~cm}$ with 100 times less sensitivity (Figure 5). Beyond that point, any attempt for longer Fabry-Perot cavity fabrication will result not only in a bigger size of the device but also to a significant reduction of its sensitivity. On the other hand, using PF-POF based interferometric sensors at $\lambda=1.550 \mu \mathrm{m}$ with $90 \%$ reflectivity mirrors, longer Fabry-Perot cavities can be created (Figure 6) because of the fibre's lower attenuation. 


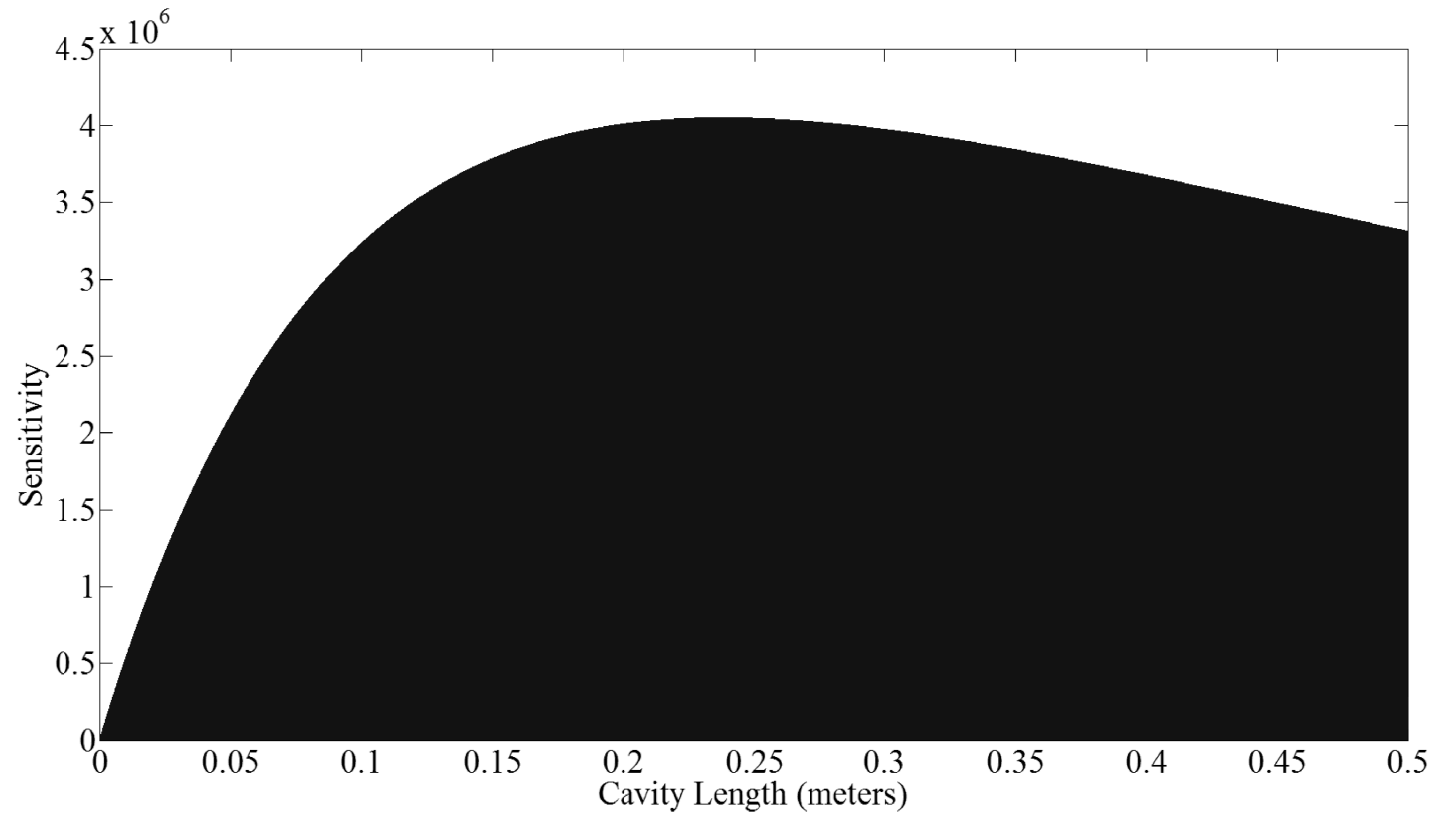

Figure 3: PMMA-POF Fabry-Perot at $0.850 \mu \mathrm{m}$ with $80 \%$ reflectivity mirrors

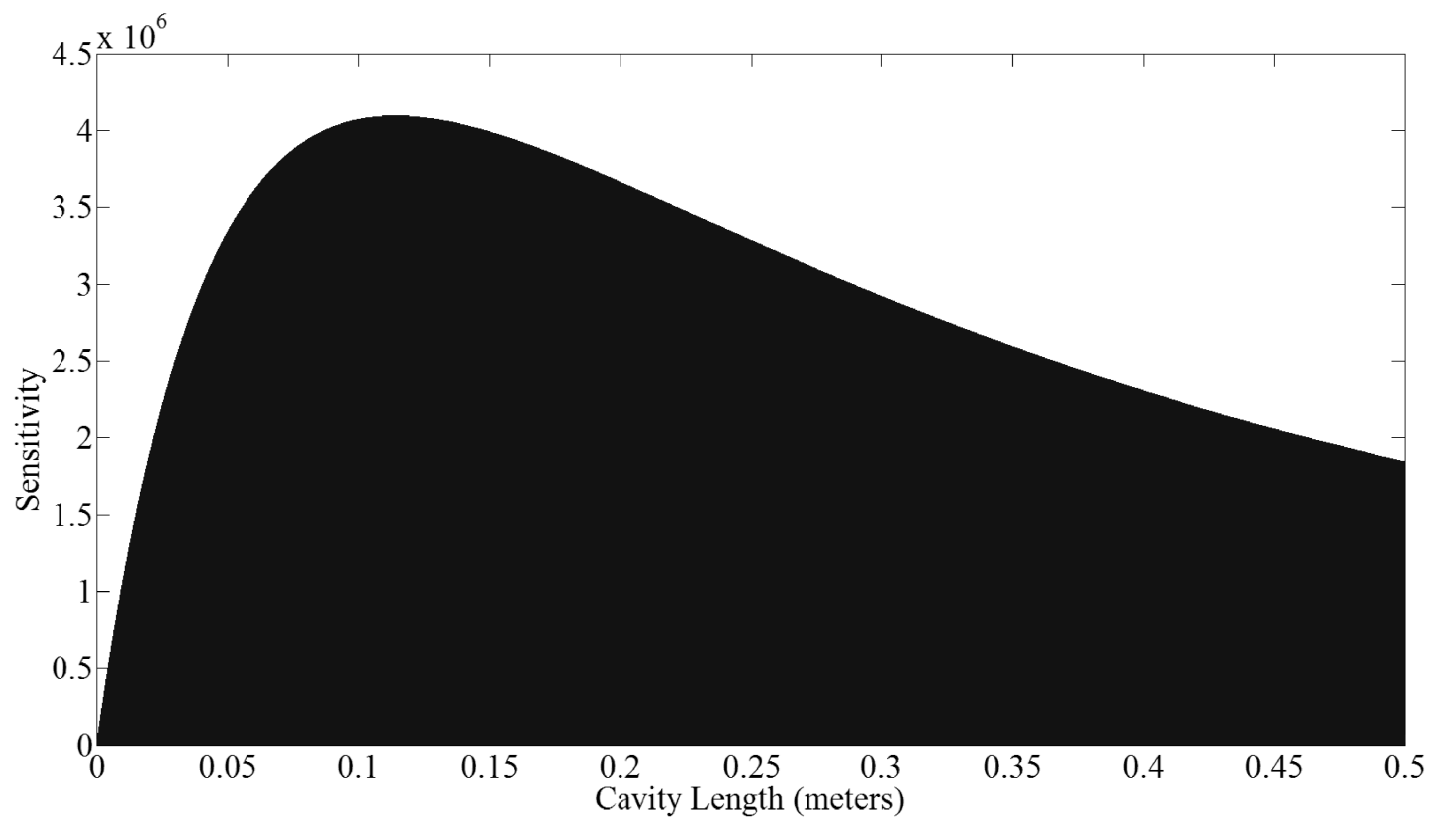

Figure 4: PMMA-POF Fabry-Perot at $0.850 \mu \mathrm{m}$ with $90 \%$ reflectivity mirrors 


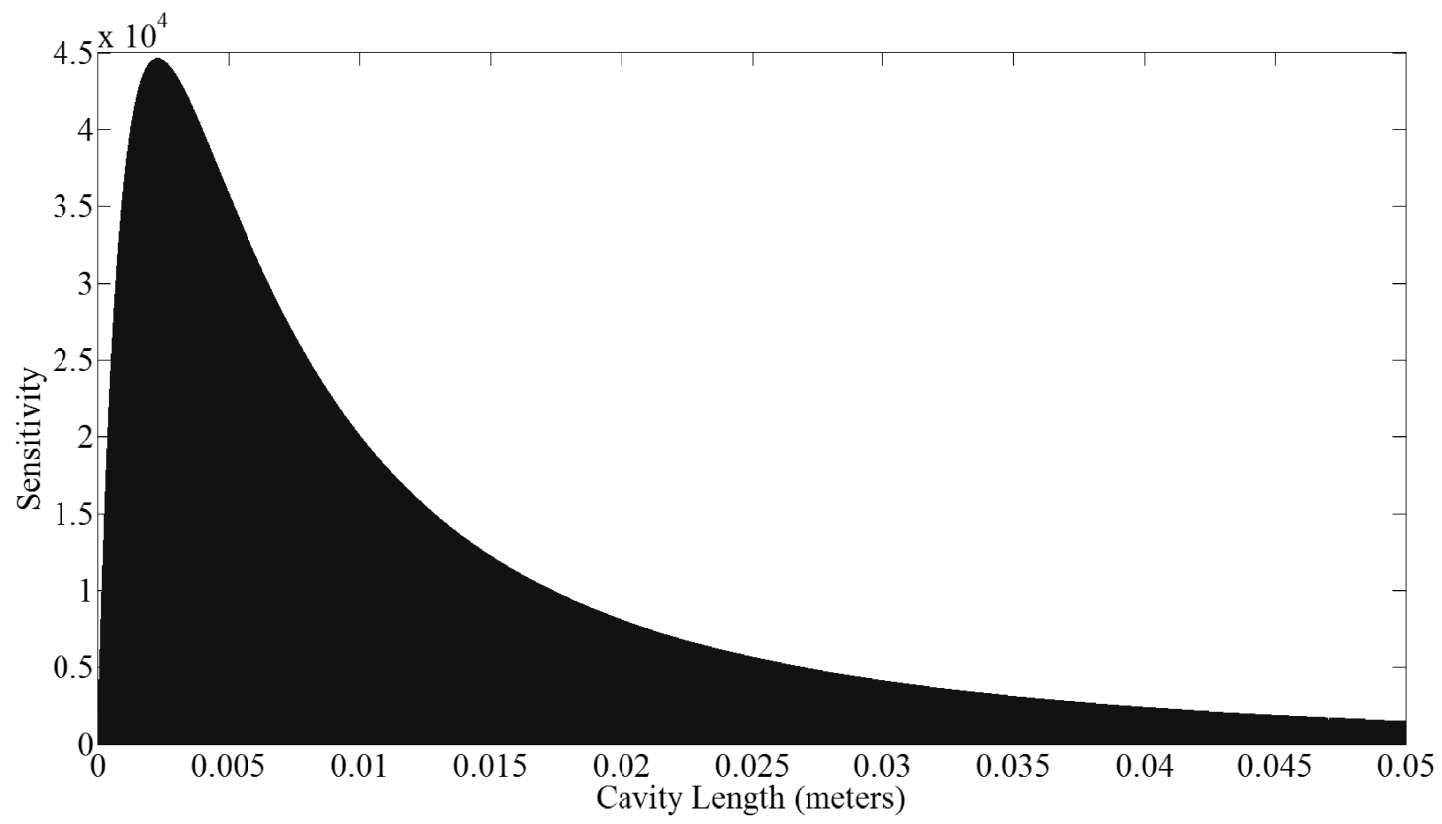

Figure 5: PMMA-POF Fabry-Perot at $1.550 \mu \mathrm{m}$ with $90 \%$ reflectivity mirrors

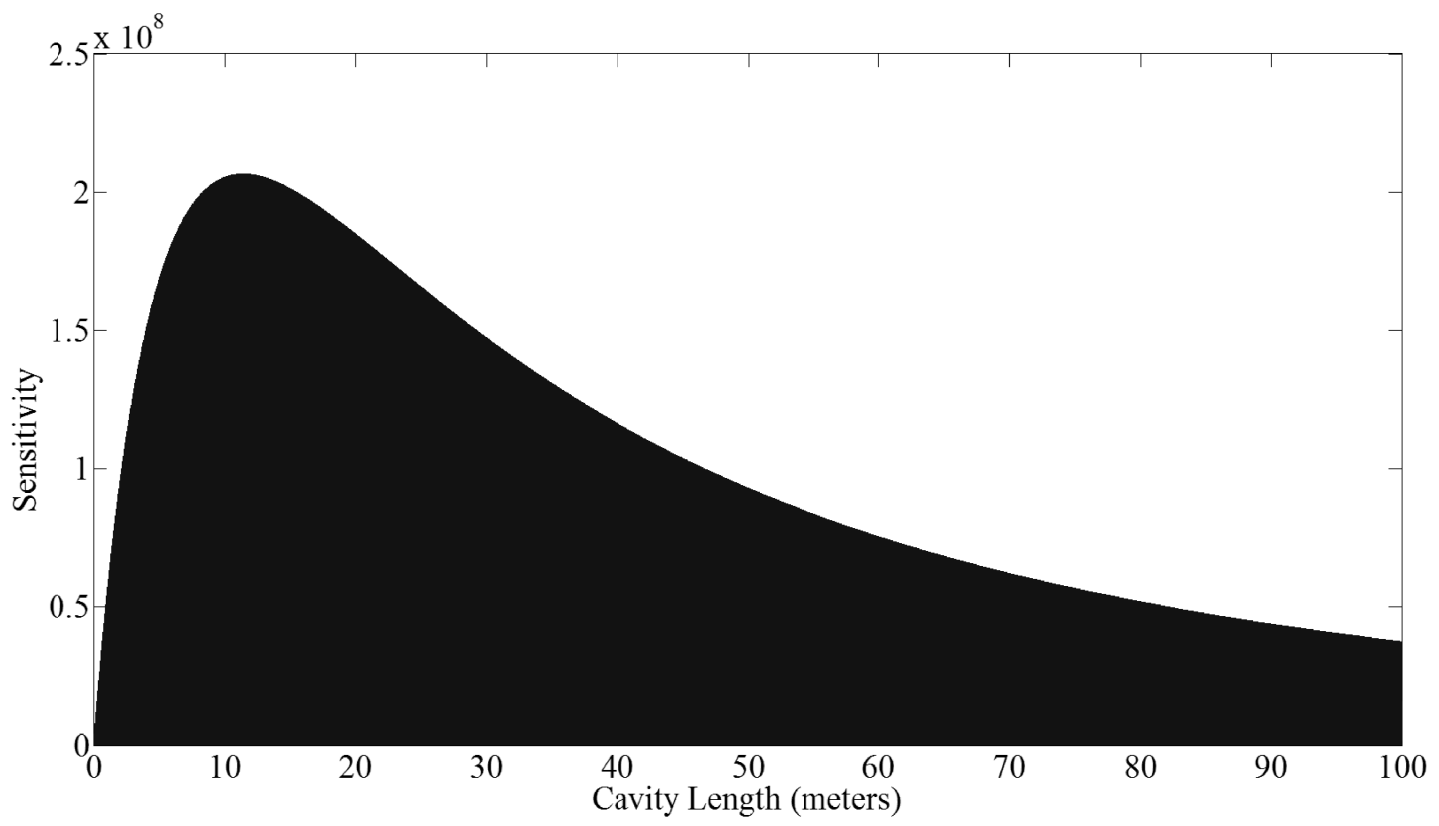

Figure 6: PF-POF Fabry-Perot at $1.550 \mu \mathrm{m}$ with $90 \%$ reflectivity mirrors

The optimum cavity lengths and the achievable maximum sensitivities of a POF based Fabry-Perot interferometers with $90 \%$ reflectivity mirrors are depicted in Table 2 . The respective optical path lengths for two-beam interferometers can be seen in Table 3. 
Table 2: Optimum optical cavity length of a Fabry-Perot interferometer with $90 \%$ reflectivity mirrors

\begin{tabular}{|c|c|c|c|c|c|c|}
\cline { 2 - 7 } \multicolumn{1}{c|}{} & \multicolumn{2}{c|}{ PMMA } & \multicolumn{2}{c|}{ PF-POF (CYTOP) } & \multicolumn{2}{c|}{ Fused Silica } \\
\cline { 2 - 7 } & $\begin{array}{c}\text { Maximum } \\
\text { sensitivity }\end{array}$ & $\begin{array}{c}\text { Optimum } \\
\text { Length } \\
\text { (meters) }\end{array}$ & $\begin{array}{c}\text { Maximum } \\
\text { sensitivity }\end{array}$ & $\begin{array}{c}\text { Optimum } \\
\text { Length } \\
\text { (meters) }\end{array}$ & $\begin{array}{c}\text { Maximum } \\
\text { sensitivity }\end{array}$ & $\begin{array}{c}\text { Optimum } \\
\text { Length } \\
\text { (meters) }\end{array}$ \\
\hline$\lambda=0.650 \mu \mathrm{m}$ & $5.3687 \mathrm{e}+07$ & 1.1391 & $1.6477 \mathrm{e}+08$ & 3.8010 & $2.6277 \mathrm{e}+09$ & 64.778 \\
\hline$\lambda=0.850 \mu \mathrm{m}$ & $4.0963 \mathrm{e}+06$ & 0.1143 & $1.8877 \mathrm{e}+08$ & 5.6672 & $7.0244 \mathrm{e}+09$ & 227.95 \\
\hline$\lambda=1.050 \mu \mathrm{m}$ & $8.2803 \mathrm{e}+05$ & 0.0285 & $2.4420 \mathrm{e}+08$ & 9.1054 & $1.1363 \mathrm{e}+10$ & 457.36 \\
\hline$\lambda=1.350 \mu \mathrm{m}$ & $5.1342 \mathrm{e}+04$ & 0.0022 & $2.3728 \mathrm{e}+08$ & 11.375 & $1.4714 \mathrm{e}+10$ & 758.74 \\
\hline$\lambda=1.550 \mu \mathrm{m}$ & $4.4624 \mathrm{e}+04$ & 0.0022 & $2.0659 \mathrm{e}+08$ & 11.390 & $1.9208 \mathrm{e}+10$ & 1132.5 \\
\hline
\end{tabular}

Table 3: Optimum optical path length of a two-beam interferometer

\begin{tabular}{|c|c|c|c|c|c|c|}
\cline { 2 - 7 } \multicolumn{1}{c|}{} & \multicolumn{2}{c|}{ PMMA } & \multicolumn{2}{c|}{ PF-POF (CYTOP) } & \multicolumn{2}{c|}{ Fused Silica } \\
\cline { 2 - 7 } & $\begin{array}{c}\text { Maximum } \\
\text { sensitivity }\end{array}$ & $\begin{array}{c}\text { Optimum } \\
\text { Length } \\
\text { (meters) }\end{array}$ & $\begin{array}{c}\text { Maximum } \\
\text { sensitivity }\end{array}$ & $\begin{array}{c}\text { Optimum } \\
\text { Length } \\
\text { (meters) }\end{array}$ & $\begin{array}{c}\text { Maximum } \\
\text { sensitivity }\end{array}$ & $\begin{array}{c}\text { Optimum } \\
\text { Length } \\
\text { (meters) }\end{array}$ \\
\hline$\lambda=0.650 \mu \mathrm{m}$ & $4.1183 \mathrm{e}+08$ & 21.70 & $1.2639 \mathrm{e}+09$ & 72.38 & $2.0150 \mathrm{e}+10$ & 1243.9 \\
\hline$\lambda=0.850 \mu \mathrm{m}$ & $3.1423 \mathrm{e}+07$ & 2.171 & $1.4480 \mathrm{e}+09$ & 108.56 & $5.3884 \mathrm{e}+10$ & 4343.1 \\
\hline$\lambda=1.050 \mu \mathrm{m}$ & $6.3518 \mathrm{e}+06$ & 0.543 & $1.8733 \mathrm{e}+09$ & 173.75 & $8.7167 \mathrm{e}+10$ & 8663.4 \\
\hline$\lambda=1.350 \mu \mathrm{m}$ & $3.9384 \mathrm{e}+05$ & 0.043 & $1.8201 \mathrm{e}+09$ & 217.11 & $1.1287 \mathrm{e}+11$ & 14457.9 \\
\hline$\lambda=1.550 \mu \mathrm{m}$ & $3.4231 \mathrm{e}+05$ & 0.043 & $1.5848 \mathrm{e}+09$ & 217.25 & $1.4735 \mathrm{e}+11$ & 21718.5 \\
\hline
\end{tabular}

\subsection{Strain and stress sensitivity}

Neglecting attenuation for the moment, it has been found [13] that PMMA based interferometers have $\sim 14 \%$ more strain sensitivity than fused silica ones because of their different strain coefficients. Taking losses into account, the strain sensitivity ratio of polymer and silica based sensors begins to drop as the optical cavity length increases. For example, a PMMA POF based two-beam interferometer operating at $\lambda=0.850 \mu \mathrm{m}$ has been found to have higher strain sensitivity compared to its silica counterpart if the optical length is less than $26 \mathrm{~cm}$, despites the higher losses.

However, the stress sensitivity of POF based sensors can be even much higher than SOF based devices. The Young modulus of silica and PMMA is $73 \mathrm{GPa}$ and $3.3 \mathrm{GPa}$ respectively, which means approximately 25 times more elasticity for PMMA [14]. Young modulus is related with strain and stress by this equation:

$$
E=\frac{\sigma}{\varepsilon}
$$

where $\sigma$ and $\varepsilon$ are stress and strain respectively. Therefore, the stress sensitivity can be calculated by:

$$
\frac{\partial I_{t}}{\partial \sigma}=\frac{\partial I_{t}}{\partial \varepsilon} \frac{1}{E}
$$

For instance, the stress sensitivity of a two-beam interferometer operating at $\lambda=1.550 \mu \mathrm{m}$ can be seen in Table 4 . It shows those regimes where POF based two-beam interferometric sensor offer enhanced performance compared to SOF. Stress sensitivity of a of Fabry-Perot interferometer with $90 \%$ reflectivity mirrors at $\lambda=1.550 \mu \mathrm{m}$ can be seen in Table 5 . Some regimes can be seen where POF based Fabry-Perot interferometric sensors offer enhanced performance compared to SOF. 
Table 4: Stress sensitivity of two-beam interferometer at $\lambda=1.550 \mu \mathrm{m}$

\begin{tabular}{|c|c|c|c|c|c|c|}
\cline { 2 - 7 } \multicolumn{1}{c|}{} & \multicolumn{2}{c|}{ PMMA } & \multicolumn{2}{c|}{ PF-POF (CYTOP) } & \multicolumn{2}{c|}{ Fused Silica } \\
\hline $\begin{array}{c}\text { Optical } \\
\text { Length } \\
\text { (meters) }\end{array}$ & $\begin{array}{c}\text { Stress } \\
\text { sensitivity } \\
\text { per MPa }\end{array}$ & $\begin{array}{c}\text { Sensitivity } \\
\text { ratio with } \\
\text { silica }\end{array}$ & $\begin{array}{c}\text { Stress } \\
\text { sensitivity } \\
\text { per MPa }\end{array}$ & $\begin{array}{c}\text { Sensitivity } \\
\text { ratio with } \\
\text { silica }\end{array}$ & $\begin{array}{c}\text { Stress } \\
\text { sensitivity } \\
\text { per MPa }\end{array}$ & $\begin{array}{c}\text { Sensitivity } \\
\text { ratio with } \\
\text { silica }\end{array}$ \\
\hline 0.001 & 6.35 & 25.4 & 6.01 & 24.0 & 0.25 & 1 \\
\hline 0.01 & 51.6 & 20.5 & 60.1 & 23.8 & 2.52 & 1 \\
\hline 0.1 & 64.0 & 2.5 & 600.9 & 23.7 & 25.3 & 1 \\
\hline 1 & 0.0006 & $\sim 0$ & 5969.7 & 23.6 & 252.7 & 1 \\
\hline 10 & $\sim 0$ & $\sim 0$ & 56667 & 22.4 & 2527 & 1 \\
\hline
\end{tabular}

Table 5: Stress sensitivity of Fabry-Perot interferometer with $90 \%$ reflectivity mirrors at $\lambda=1.550 \mu \mathrm{m}$

\begin{tabular}{|c|c|c|c|c|c|c|}
\cline { 2 - 7 } \multicolumn{1}{c|}{} & \multicolumn{2}{c|}{ PMMA } & \multicolumn{2}{c|}{ PF-POF (CYTOP) } & \multicolumn{2}{c|}{ Fused Silica } \\
\hline $\begin{array}{c}\text { Optical } \\
\text { Length } \\
\text { (meters) }\end{array}$ & $\begin{array}{c}\text { Stress } \\
\text { sensitivity } \\
\text { per MPa }\end{array}$ & $\begin{array}{c}\text { Sensitivity } \\
\text { ratio with } \\
\text { silica }\end{array}$ & $\begin{array}{c}\text { Stress } \\
\text { sensitivity } \\
\text { per MPa }\end{array}$ & $\begin{array}{c}\text { Sensitivity } \\
\text { ratio with } \\
\text { silica }\end{array}$ & $\begin{array}{c}\text { Stress } \\
\text { sensitivity } \\
\text { per MPa }\end{array}$ & $\begin{array}{c}\text { Sensitivity } \\
\text { ratio with } \\
\text { silica }\end{array}$ \\
\hline 0.001 & 11.04 & 14.15 & 18.52 & 23.74 & 0.78 & 1 \\
\hline 0.01 & 6.08 & 0.781 & 184.9 & 23.76 & 7.78 & 1 \\
\hline 0.1 & 0.06 & 0.001 & 1828 & 23.49 & 77.8 & 1 \\
\hline 1 & $\sim 0$ & $\sim 0$ & 16285 & 20.95 & 777.3 & 1 \\
\hline 10 & $\sim 0$ & $\sim 0$ & 62242 & 8.10 & 7681 & 1 \\
\hline
\end{tabular}

\section{CONCLUSION}

The described numerical model for Fabry-Perot and two-beam interferometers has been used to determine their optimum cavity length for maximum strain sensitivity. Results show those regimes where interferometric sensors constructed in polymer optical fibres can offer enhanced stress sensitivity over their silica counterparts.

\section{ACKNOWLEDGMENT}

The research leading to these results has received funding from the People Programme (Marie Curie Actions) of the European Union's Seventh Framework Programme FP7/2007-2013/ under REA grant agreement No. 608382.

\section{REFERENCES}

[1] M. C. J. Large, J. Moran, and L. Ye, "The role of viscoelastic properties in strain testing using microstructured polymer optical fibres (mPOF)," Measurement Science \& Technology, 20, (2009).

[2] S. Kiesel, P. Van Vickle, K. Peters et al., "Intrinsic polymer optical fiber sensors for high-strain applications," 6167, 616713-616713-11 (2006).

[3] A. Stefani, S. Andresen, W. Yuan et al., "Dynamic Characterization of Polymer Optical Fibers," Ieee Sensors Journal, 12, 3047-3053 (2012).

[4] C. D. Butter, and G. B. Hocker, "Fiber optics strain gauge," Applied Optics, 17(18), 2867-2869 (1978).

[5] H. P. A. van den Boom, W. Li, P. K. van Bennekom et al., "High-capacity transmission over polymer optical fiber," Selected Topics in Quantum Electronics, IEEE Journal of, 7(3), 461-470 (2001).

[6] T. Ishigure, Y. Koike, and J. W. Fleming, "Optimum index profile of the perfluorinated polymer-based GI polymer optical fiber and its dispersion properties," Journal of Lightwave Technology, 18(2), 178-184 (2000).

[7] N. Sultanova, S. Kasarova, and I. Nikolov, "Dispersion properties of optical polymers," Acta Physica Polonica A, 116(4), 585-587 (2009).

[8] I. H. Malitson, "Interspecimen Comparison of the Refractive Index of Fused Silica," Journal of the Optical Society of America, 55(10), 1205-1208 (1965). 
[9] A. Bertholds, and R. Dandliker, "Determination of the individual strain-optic coefficients in single-mode optical fibres," Lightwave Technology, Journal of, 6(1), 17-20 (1988).

[10] A. Makishima, and J. D. Mackenzie, "Calculation of bulk modulus, shear modulus and Poisson's ratio of glass," Journal of Non-Crystalline Solids, 17(2), 147-157 (1975).

[11] R. M. Waxler, D. Horowitz, and A. Feldman, "Optical and physical parameters of Plexiglas 55 and Lexan," Applied Optics, 18(1), 101-104 (1979).

[12] D. D. Raftopoulos, D. Karapanos, and P. S. Theocaris, "Static and dynamic mechanical and optical behaviour of high polymers," Journal of Physics D: Applied Physics, 9(5), 869 (1976).

[13] M. Silva-Lopez, A. Fender, W. N. Macpherson et al., "Strain and temperature sensitivity of a single-mode polymer optical fiber," Optics Letters, 30, 3129-3131 (2005).

[14] J. G. A. Griffiths, "Tables of physical and chemical constants. By G. W. C. Kaye and T. H. Laby," The Analyst, 73(873), 704 (1948). 